\title{
Quantum dot solar cell studies on the influence of Cadmium Selenide(CdSe)QDs and the Zinc Sulfide(ZnS)QDs in the photoanode
} \author{
Mohamad Taib ${ }^{1,2}$ Ab Malik Marwan Ali ${ }^{1}$, and Rosnah Zakaria ${ }^{1,2, *}$ \\ ${ }^{1}$ Faculty of Applied Sciences, Universiti Teknologi MARA, 40450 Shah Alam, Selangor, Malaysia \\ ${ }^{2}$ Institute of Science, Universiti Teknologi MARA, 40450 Shah Alam, Selangor, Malaysia \\ ${ }^{3}$ Faculty of Art and Design, Universiti Teknologi MARA, 40450 Shah Alam, Selangor, Malaysia \\ ${ }^{4}$ Faculty of Defence Science \& Technology, Universiti Pertahanan Nasional Malaysia, 57000
}

Mohammad Azren Saad ${ }^{1, *}$, Noor Syafiqah Samsi ${ }^{1}$, Oskar Hasdinor Hassan ${ }^{3}$, Muhd Zu Azhan Yahya ${ }^{2,4}$, Mohamad Fariz

\begin{abstract}
The mixture between the difference semiconductor quantum dot sensitizer which is cadmium selenide(CdSe) and zinc sulfide $(\mathrm{ZnS})$ into the Dye-synthesis solar cell (DSSCs) can affect the value of resistance and capacity photoanode in the system.In this experiment, each sample consists difference weight percent of Zinc sulfide and the constant weight percent of CdSe. Docter blade technique is used to stick and spread evenly the mixture CdSe/ZnS QD on the surface of the thin film. To prove the assembled of CdSe/ZnS on the thin film were observed using Scanning Electron Microscopy (SEM). The resistance and capacity of the photoanode were characterized by using impedance spectroscopy(EIS). The smallest resistance is $37.1 \mathrm{k} \Omega$ produce by $\mathrm{CdSe} / \mathrm{ZnS}(20 \mathrm{wt} \%)$ and the largest resistance $825 \mathrm{~K} \Omega$ produce by $\mathrm{CdSe} / \mathrm{ZnS}(50 \mathrm{wt} \%)$ while the highest capacity is $12 \mu \mathrm{F}$ in the $\mathrm{CdSe} / \mathrm{ZnS}(40 \mathrm{wt} \%)$ and the lowest capacity is $\mathrm{CdSe} / \mathrm{ZnS}(20 \mathrm{wt} \%)$ which is $538 \mathrm{nF}$. The most suitable composition to be used as photoanode is $\mathrm{CdSe} / \mathrm{ZnS}(40 \mathrm{wt} \%$ ) because it has high capacity and low resistance.
\end{abstract}

\section{Introduction}

Nowadays the world is facing the energy crisis, attracted attention of many researchers to study an alternative sources. Solar energy is an abundant energy and one of the most suitable renewables that could replace the hydrocarbon. DSSCs consist four main part which is an anode, cathode, sensitizing dye, and electrolyte. Anode electrode basically contains Indium tin oxide(ITO)glass, covers by titanium dioxide $\left(\mathrm{TiO}_{2}\right)$ on the conductive surface of the ITO glass[1].

The use of semiconductor as quantum dots as photoanode in Dye-sensitized solar cells(DSSCs) devices may reduce pollution and low cost-effective in converting solar energy to electric energy[2,3]. The nanoparticle of quantum dot can gives high photostability, wider absorbance spectrum and resistance to photobleaching and make it suitable to be a synthesizer in a photoanode of DSSCs[4]. The function of photoanode is to produce the current by emitting the electron from their valence shell into the conducting band[5].

$\mathrm{CdSe} / \mathrm{ZnS}$ is the one of the QDs, has a very small band gap that can absorb a very wide absorbance spectrum to excited electron producing the hole on the surface on the sample[3].This process is called the recombination process. CdSe QDs alone can be toxic toward the biological environment. However, by doping $\mathrm{ZnS}$ with CdSe it can lower down the toxicity in $\mathrm{CdSe}[6]$.
$\mathrm{TiO}_{2}$ with injection of dye is a medium to absorb light and excite electrons at below than visible light at 3.2 eV[7]. The converted energy will be used by the electron to release from the valence band into the conducting band. The flow of the electron will produce current in the circuit. On the other hand, the amount of light absorption is still low and this is the reason why combination of semiconductor quantum dot QDs into photoanode were introduced[8].

Resistance is the factor that slow down the flow of electron in the sample, if the sample have the low value of resistance it will produce a high current. Capacity is the ability of sample to store energy, more energy can be store in the sample that have high capacity[10].

\section{Methodology}

The conductivity of CdSe/ZnS QDs will be determined through the methodology of preparation of the material. Optimum wt $\%$ of the combination can give more number of hole in the structure which can increase the conductivity of the photoanode[9, 5].

\subsection{Preparation of $\mathrm{CdSe} / \mathrm{ZnS}$ solution}

A control mass of ruthenium-based dye (N719) at $0.045 \mathrm{~g}$ was added into $9 \mathrm{ml}$ of ethanol and stirred using magnetic

*Corresponding author: azrensaad@yahoo.com.my 
stirrer for 24 hours The mass of $\mathrm{CdSe} / \mathrm{ZnS}$ was calculated to make it as $10-50 \mathrm{wt} \%$ using the Eq 1. Detail mass was tabulated in Table1. These samples were prepared in a dark environment.

$$
W c d s e / z n s=((w t \%)(w n 719)) /(1-(w t \%))
$$

Table 1. Composition of the sample prepared with different percentage of CdSe/ZnS QD.

\begin{tabular}{|c|c|c|c|}
\hline Sample & $\begin{array}{c}\text { CdSe/Zns } \\
\text { QDs } \\
\text { compositio } \\
\mathrm{n}(\mathrm{wt} \%)\end{array}$ & $\begin{array}{c}\text { Mass of } \\
\text { N719dye } \\
\text { powder }\end{array}$ & $\begin{array}{c}\text { Mass of } \\
\text { CdSe/ ZnS } \\
\text { QDs powder } \\
(\mathrm{g})\end{array}$ \\
\hline $\mathrm{A}$ & 10 & 0.045 & 0.005 \\
\hline $\mathrm{B}$ & 20 & 0.045 & 0.011 \\
\hline $\mathrm{C}$ & 30 & 0.045 & 0.019 \\
\hline $\mathrm{D}$ & 40 & 0.045 & 0.030 \\
\hline $\mathrm{E}$ & 50 & 0.045 & 0.045 \\
\hline
\end{tabular}

\section{2 preparation of photoanode}

The ITO glass was clean using an ultrasonic bath. The $\mathrm{TiO}_{2}$ paste was coated onto conductive ITO glass using the doctor blade technique. This ITO's coated glass then left to dry for 1 day in the room temperature.

The dry coated glass with $\mathrm{TiO}_{2}$ was immersed in the mixture solution of $\mathrm{N} 719 / \mathrm{CdSe}-\mathrm{ZnS}$ in dark environment for 24 hours. Then, the sample was clean using ethanol to remove the residue and dried in the oven at $60{ }^{\circ} \mathrm{C}$.

\subsection{Characterization ITO/TiO2/N719/CdSe photoanode}

\subsubsection{Scanning electron microscope (SEM)}

Scanning electron microscope (SEM) used to analyze the appearance of $\mathrm{ZnS}$ QDs and CdSe QDs as glowing materials on the surface of the $\mathrm{TiO}_{2}$ glass. This photoanode was analyzed using Energy Dispersive X-ray (SEM/EDX) spectroscopy to see the existence of $\mathrm{CdSe} / \mathrm{ZnS}$ QDs on the surface of the photoanode [10].

\subsubsection{Electrochemical Impedance Spectroscopy}

The Electrochemical Impedance Spectroscopy(EIS) method using Potentiostat Galvanostat will produce ColeCole plot to each sample. This plot shows the information about the capacity and resistance in the sample[9]. The electrical impedance spectroscopy, EIS is an instrument to measure the resistance and capacity analysis of cosensitized [11]. The QDs (ITO/TiO2/N719-CdSe/ZnS) were used as a working electrode $\left(\mathrm{W}_{\mathrm{e}}\right)$, a platinum electrode is act as counter electrode $\left(\mathrm{C}_{\mathrm{e}}\right)$ and $\mathrm{Ag} / \mathrm{AgCI} / 3 \mathrm{MKCI}$ is be the reference electrode. The model was used iodide/iodine as electrolyte of the cell. The characterization was used the frequency range of 0.009 $100000 \mathrm{~Hz}$ for 50 readings. The Cole-Cole plot were analyzed using equivalent circuit by Nova software.

\section{Results and Discussions}

Figure1 shows the scanning electron microscope (SEM) at the resolution of $128 \times 128$ pixels, using the Energy Dispersive X-ray (SEM/EDX)spectroscopy, proved that the assembly of $\mathrm{CdSe} / \mathrm{ZnS}$ QDs onto $\mathrm{TiO}_{2}$. This finding is important to improve the efficiency of DQs $\mathrm{ZnS} / \mathrm{CdSe}$ Photoanode in the QDSSCs.

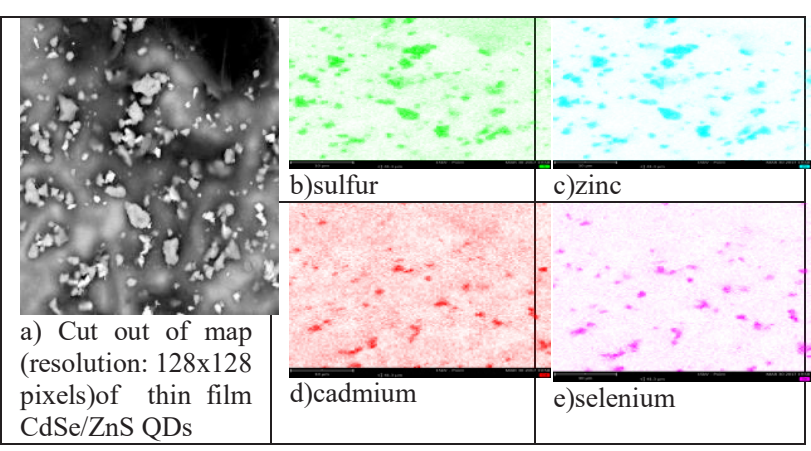

Fig. 1: The image of QDs $(\mathrm{CdSe} / \mathrm{ZnS})$ on the surface of Photoanode

The Figure 1b, 1c, 1d, 1e shows the different color which is represented the different type of material. Figure $1 \mathrm{~b}$ shows the location of blue color represented the location of zinc and green spot in the figure 1c represent the location of sulfur and CdSe trace in figure 1d and 1e.Figure $1 \mathrm{~d}$ show the presence of $\mathrm{Cd}$ (cadmium) and figure 1e show the presence of Se (selenide). The pattern dot color in each figure proves the element are interconnected each other, for example, figure $1 \mathrm{~b}$ and $1 \mathrm{c}$ have the same pattern this meant that this material is bonding each other and form $\mathrm{ZnS}$.

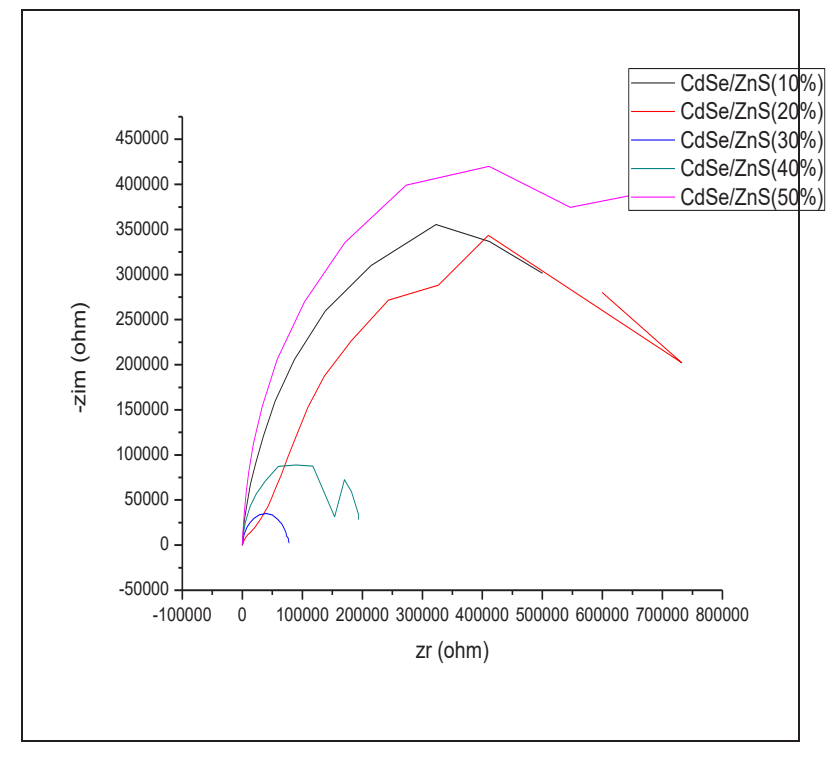

Fig. 2: The EIS graph of CdSe/ZnS QDs with different weight percent $(\mathrm{Wt} \%)$

The semicircle shown in graph 1 shows the difference value of resistance between the sample. The resistance value of each sample can be analyzed from the graph by 
measuring the diameter of the semicircle. The value of real impendence $(\mathrm{Zr})$ represents the value of the resistance in the sample. The imaginary impendence shows the capacitance of the sample. This capacitance importance to analyze the ability of the sample to store the energy of electric charge. This graph proves that all sample produce the parallel resistance and capacity to each other and have single circuits, this single circuit represents the reaction of current flow in the photoanode and electrolyte. The resistance was calculated automatically by EIS device, by using the fitting and simulation setting on the device, it can create the circuit that is associated with our sample. This study used $\mathrm{R}(\mathrm{RC})$ meant single circuits.

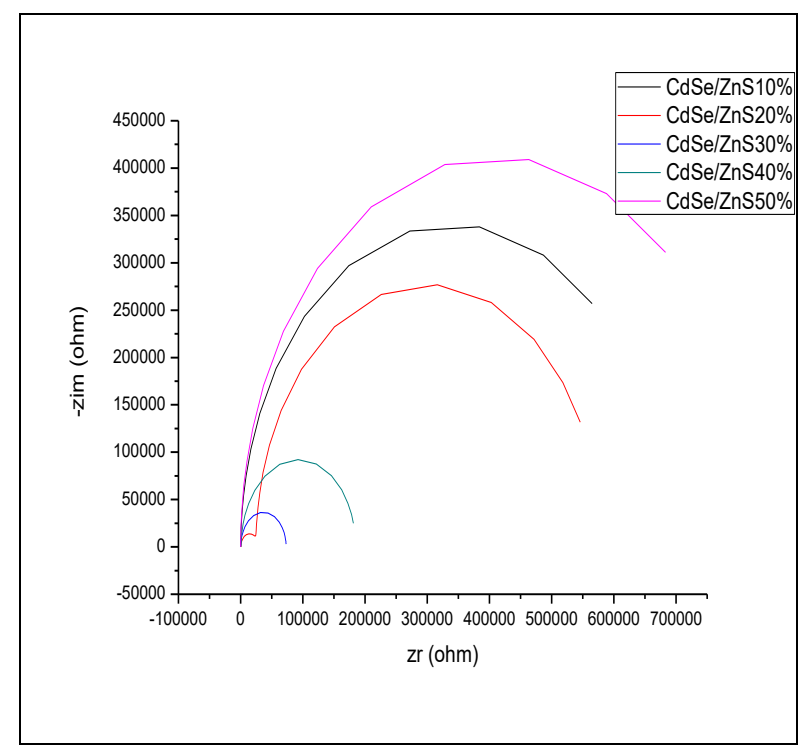

Fig. 3: The fitting EIS graph of CdSe/ZnS QDs with different weight percent $(\mathrm{Wt} \%)$

The fitting EIS graph for Figure 3 was drawn using the EIS fitting simulation. This simulation helps to find the magnitude of resistance in the sample. In Figure 3 each of the samples shows the difference semicircle size, from observation it clearly found that the largest semicircle is produced by the combination between $\mathrm{CdSe} / \mathrm{ZnS}$ (50 $\mathrm{wt} \%)$. The curve of $\mathrm{CdSe} / \mathrm{ZnS}(10 \mathrm{wt} \%), \mathrm{CdSe} / \mathrm{ZnS}(20$ $\mathrm{wt} \%)$ is bigger compared to the $\mathrm{CdSe} / \mathrm{ZnS}(30 \mathrm{wt} \%)$, $\mathrm{CdSe} / \mathrm{ZnS}(40 \mathrm{wt} \%)$, from this result it show that $50 \%, 10 \%$ and $20 \mathrm{wt} \%$ of $\mathrm{ZnS}$ in the photoanode produce the higher resistance compared to the $30 \mathrm{wt} \%$ and $40 \mathrm{wt} \%$ $\mathrm{ZnS}$. The higher resistance in the material will slow down the movement of the electron, as the result, this will lower down the current produced by the system.

Resistance is the factor that can reduce the flow of electron as the result it will lower down the value of current. The factor that increases the value resistance is the structure of the material. In Dye-synthesis solar cell the structure that is needed to increase the flow of electron is the hole. The hole is the place for an electron to jump from one atom to another until it reaches anode terminal. The value of resistance in table 2 clearly show that the highest resistance is $\mathrm{CdSe} / \mathrm{ZnS}(50 \mathrm{wt} \%)$. The value of resistance in the $\mathrm{CdSe} / \mathrm{ZnS}(50 \mathrm{wt} \%)$ is $825 \mathrm{k} \Omega$.Photo anode with $10 \% \mathrm{ZnS}$ produces a second larger value of resistance compared to the first one. The lowest resistance is $20 \mathrm{wt} \% \mathrm{ZnS}$ with $37.1 \mathrm{k} \Omega$ From the graph in figure 3,20 $\mathrm{wt} \% \mathrm{ZnS}$ produce two semicircles $37.1 \mathrm{k} \Omega$ is the value of resistance of the small semicircles.

Table 2. Value of resistance and capacity in CdSe/ZnS QDs with different weight percent $(\mathrm{Wt} \%)$

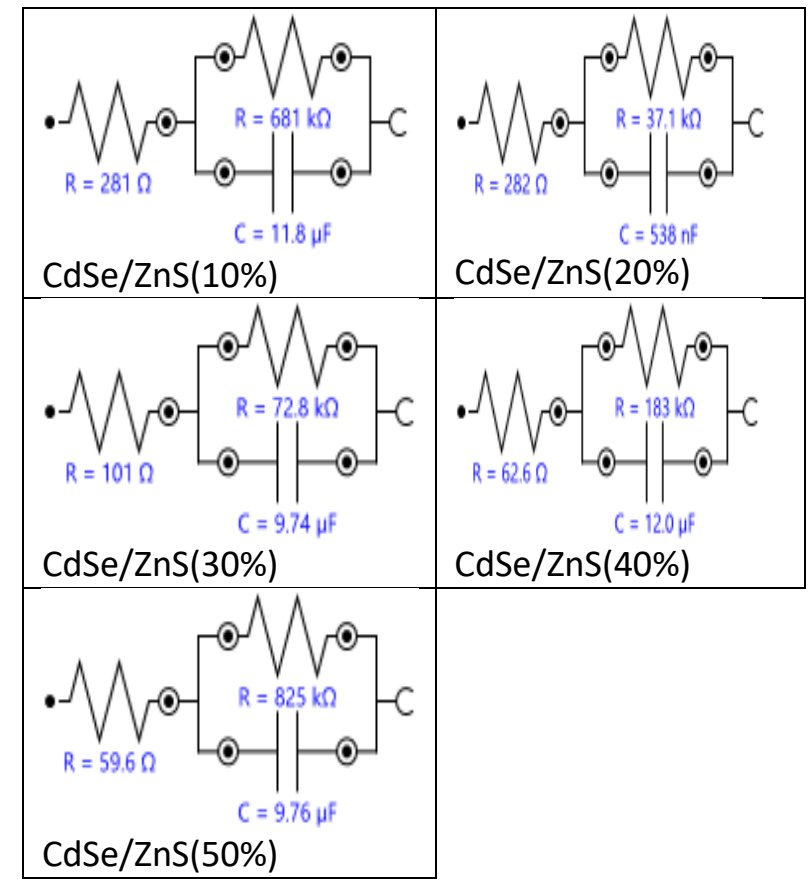

Note: Adapted from potentiostat galvanostat (Auto Lab), using Nova software single circuit

Capacity is the ability of a system to store an electric charge. Table 2 show the highest capacity is $\mathrm{CdSe} / \mathrm{ZnS} 40$ $\mathrm{wt} \%$ with the $12 \mu \mathrm{F}$. The second large capacity produce is $\mathrm{CdSe} / \mathrm{ZnS}(10 \mathrm{wt} \%)$ and the value of capacitance is 11.8 $\boldsymbol{\mu} \mathbf{F}$. The capacity in $\mathrm{CdSe} / \mathrm{ZnS}(20 \mathrm{wt} \%)$ is $538 \mathrm{nF}$, this is the lowest capacity produce compared to another sample.

\section{Conclusions}

The ZnS QDs combine with the CdSe QDs dissolve in the N719 effect the value of resistance and capacity. Electrochemical Impedance Spectroscopy (EIS) of varying the $\mathrm{wt} \%$ of $\mathrm{ZnS}$, found that the $40 \mathrm{wt} \%$ of $\mathrm{ZnS}$ is the most suitable to be added to the dye of photoanode because it produces the low resistant of $183 \mathrm{k} \Omega$ and high capacitance which is $12 \mu \mathrm{F}$ compared to another sample. Furthermore, The SEM of ZnS / CdSe/N719 showed the existence of $\mathrm{CdSe}$ and Zinc sulfide and interconnected each other on the surface of ITO glass.

This work was partially supported by the Ministry of Higher Education (MOHE) Malaysia and financial support under the project FRGS/1/2015/SG06/UITM/02/5 grant and acknowledge the Universiti Teknologi MARA (UiTM) for the facilities provided.

\section{References}

1. M. a M.Al-Alwani, A. B.Mohamad, N. a.Ludin, A. A. H.Kadhum, \& K.Sopian,. Dye-sensitised solar 
cells: Development, structure, operation principles, electron kinetics, characterisation, synthesis materials and natural photosensitisers. Renewable and Sustainable Energy Reviews, 65, 183-213, (2016).

2. I.renewables eras-Saizarbitoria, E.Cilleruelo, \& I.Zamanillo,Public acceptance of renewables and the media: An analysis of the Spanish PV solar experience. Renewable and Sustainable Energy Reviews, 15(9), 4685-4696, (2011).

3. I. N.Obotowo, I. B.Obot, \& U. J. Ekpe,. Organic sensitizers for dye-sensitized solar cell (DSSC): Properties from computation, progress and future perspectives. Journal of Molecular Structure, (2016)

4. K.Kim, , J. E EunS, Y.Chang, , J. Kim, C. Im, \& M Lee, Electrochimica Acta ZnS-Passivated CdSe / CdS Co-sensitized Mesoporous $\mathrm{Zn} 2 \mathrm{SnO} 4$ Based Solar Cells. Electrochimica Acta, 121, 223232,(2014).

5. P. V. Kamat, (2008). Quantum Dot Solar Cells . Semiconductor Nanocrystals as Light Harvesters, 18737-18753.

6. S.Porcel, V.López-carrillo, C García-yebra, \& M.Antonio,. Supporting Information ( ) , 1-13 (2008),

7. Z. Li, Y.Xie, H.Xu, T.Wang, Z.Xu, \& H.Zhang,. Journal of Photochemistry and Photobiology A : Chemistry Expanding the photoresponse range of $\mathrm{TiO} 2$ nanotube arrays by $\mathrm{CdS} / \mathrm{CdSe} / \mathrm{ZnS}$ quantum dots co-modification. "Journal of Photochemistry \& Photobiology, A: Chemistry, (2011).

8. D.R.Ako, Peiris, U.S., P.Ekanayake, , A. L.Tan, , D. J.Young, Z.Zheng, , \& V.Chellappan,. DSSCs with $\mathrm{ZnO} @ \mathrm{TiO} 2$ core-shell photoanodes showing improved Voc: Modification of energy gradients and potential barriers with $\mathrm{Cd}$ and $\mathrm{Mg}$ ion dopants. Solar Energy Materials and Solar Cells, 157, 18-27, (2016).

9. E.Bayatloo, \& E.Saievar-iranizad,dye-sensitized solar cells by carbon nanospheres in photoanode.

10. D.Nikolopoulos, I.Valais, C.Michail, A.Bakas, C.Fountzoula, D.Cantzos, G. Panayiotakis,. Radioluminescence properties of the CdSe / $\mathrm{ZnS}$ Quantum Dot nanocrystals with analysis of longmemory trends. Radiation Measurements, 92, 19-31, (2016). 